\title{
Exploring the Relationship of Sectioning in Student Performance in a Major Subject of Bachelor of Science in Information Systems
}

\author{
Hector John T. Manaligod ${ }^{1}$, Rogelio V. del Cano ${ }^{2}$ and Jelica R. Enriquez ${ }^{3}$ \\ ${ }^{1,3}$ Computer Applications Program, School of Management and Information Technology, De La Salle-College of \\ Saint Benilde, Manila, 2544, Philippines \\ ${ }^{2}$ Information Systems Program, School of Management and Information Technology, De La Salle-College of \\ Saint Benilde, Manila, 2544, Philippines
}

\begin{abstract}
Background/Objectives: This study examined the relationship of university students' course performance in the regular block and irregular sections taking advanced programming course and the mediating effect of motivation. Methods/Statistical analysis: The respondents of the study were information systems students who were enrolled in major subjects. The independent variable was the student's course performance. The dependent variable was the section classification (i.e., regular block or irregular section). Findings: Motivation was included in the model to test whether it influences the variance found students' performance as to their sections. Logistic regression was used as statistical test for course performance and sectioning. Omnibus Test of Model Coefficient and Cox \& Snelll and Nagelkerke statistics were used for the coefficient of determination. Improvements/Applications: The study concludes that sectioning significantly relates to academic performance and grade have a modest explanatory power to sectioning. Motivation did not influence the students' grades. Certain factors of motivation such as intrinsic, self-efficacy for learning and test anxiety suggest a significant relationship with grade not necessarily based on the effect of sectioning.
\end{abstract}

\section{Index Terms}

Academic Performance, Block Section, Irregular Section, Motivation

\footnotetext{
Corresponding author : Hector John T. Manaligod, PhD

hector.manaligod@benilde.edu.ph

- Manuscript received January 22, 2019.

- Revised February 27, 2019 ; Accepted March 20, 2019

- Date of publication March 31, 2019

(C) The Academic Society of Convergence Science Inc.

2546-1583 @ 2017 IJEMR. Personal use is permitted, but republication/redistribution requires IJEMR permission.
} 


\section{INTRODUCTION}

\section{A. Background}

Studies indicate various benefits of applying block scheduling. Block schedule format produces students feel more concentrated and display lower chances of failure [1]. Reference [2] shows that block scheduling effects include improved attendance of students, lowered failure chances, and better quality of teaching. The extended periods of block scheduling allow students to have additional time for their elective courses [1,3], focus better on their studies, and improve academically[3]. Teachers have flexibility to create activities, apply new techniques in this format [3-5], and become more involved with their students [3].

Other benefits of block scheduling include improved working relationships among students and teachers[5,6], better student interaction and camaraderie [6], and "cooperative group learning" [4, p. 29]. The Center for Education Reform, as seen in $[6, p .1]$, states favorable learning environment for "team teaching, multidisciplinary classes, labs, and fieldwork". Block scheduling is also considered as cost-effective [7]. Schools are able to fully utilize the block scheduling accomplishments through comprehensive planning and implementation [8]. These changes led to an increased number of schools that implemented block scheduling [9].

Research defines block scheduling as an alternative scheduling structure where classes meet for a longer period of time[1,8]. As compared to the daily 60 minute classes, block sections meet every other day for 85 minutes[1,10]. The goals of this format are to shorten the number of classes each day by extending class periods [10], include challenging classes in the curriculum [11], and periods of block sections lessen challenges that are related with a conventional schedule [12].

On the contrary, the Center for Education Reform [13] indicates that in the initial research, block scheduling does not improve a student's class standing nor does it lead to innovative teaching techniques [2]. Planning is also not utilized effectively by the teachers [7]. Other disadvantages include "more class time was lost when students and teachers were absent" and "students were not seen daily" [4, p. 27]. An experiment [14] presents the effects of irregular sectioning; wherein students choose to enroll their sections online. This registration process enables students to freely choose their sections that are aligned to their time preferences. However, their class choices become limited as the registration process.

Studies also show that regardless on whether the schedule is block or traditional, a teacher's attitude and practices are still as important. Teachers should be able to adjust according to their students' needs [15], know how to maximize class time [16], identify the most appropriate teaching practices [12], recognize student diversity, and provide necessary assistance [9]. Ultimately, the outcome of block scheduling will be determined by the capability of the teachers and administrators to improve the quality of teaching [5].

Although there are published studies on block scheduling, the findings do not present adequate information on this type of scheduling and the "relationship between schedule and instructional strategies are mixed" [10, p. 80]. Further research is necessary in presenting concrete applications of schools using a block scheduling format [4], thorough narratives on the different types of schedules and the identified steps to train the teachers and the students of the new schedules [11], and how this format will affect the students' learning outcomes [2]. It has been suggested that teachers and school administrators should continuously document the effects of block sectioning [12].

Based on the knowledge gap that was identified from the review of the literatures, the researchers recognize the need to conduct a study to find out if regular block and irregular sectioning are factors in the performance of BSIS students enrolled in the selected major subjects.

\section{B. Statement of the Problem}

The central question which the study sought to determine is whether there is a difference in the course performance of students based on their sectioning of classes into regular or irregular block. Two specific questions are posed as follows:

1. Is there a significant relationship in the course performance of students in the regular block and irregular sections taking advanced programming course?

2. What is the degree of influence of student motivation to their course performance and their sectioning?

\section{Hypotheses}

$\mathrm{H}_{0} 1$ : The performance of students taking advance programming course is the same regardless of the sectioning.

$\mathrm{H}_{0} 2$ : Student motivation does not explain the variance in the student performance and their sectioning.

\section{Significance of the Study}

The findings of the study will benefit the administrators of the Information Systems Program in preparation of class schedules and sectioning. The 
teacher gets a better understanding on the performance of their students with respect to their sectioning. This will serve as a guide of the Registrar's Office to retain, remove, improve or generate new ideas about the usual offerings of regular blocks or irregular sections.

\section{E. Scope and Delimitation}

The study included the performances of students under the regular blocks and irregular sections of IS Advanced Programming (ISPROG3). The students was delimited to sophomore students who are enrolled to BSIS major subjects on 1st and 2nd Terms of SY 2016-2017. In addition, this study obtained the motivation of the students towards their regular block and irregular section class. This study was conducted in a university of the Philippines. The respondents are students taking Bachelor of Science in Information Systems (BSIS).

\section{F. Conceptual Framework}

Figure 1 illustrates the framework of the study. The independent variable in this study is the student course performance in advance programming. The dependent variable is the section classification i.e., regular block or irregular section. Motivation was included in the model to test whether it influences or explains the variance found students' performance as to their sections.

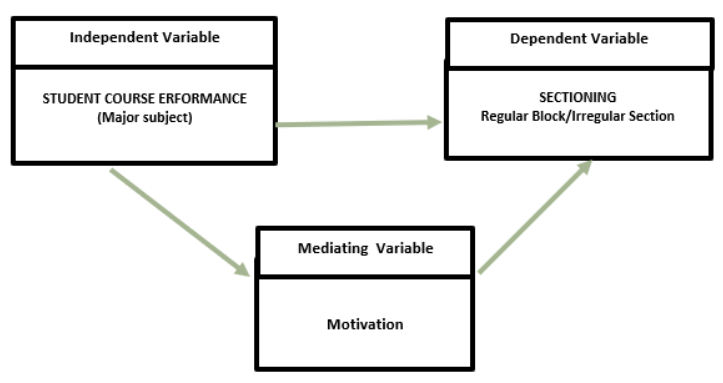

Fig. 1. Conceptual framework.

\section{Methodology}

\section{A. Operational Definition}

The student course performance refers to the final grade of the students achieved by them at the end of the term. It is an important predictor of the students' achievement enrolled either in a regular block and irregular section so they can move forward and complete their course. In this research, the final grade was based on the results of the cumulative grade earned by the students and submitted by the faculty to the Registrar's Office at the end of the term.

On the other hand, the motivational factor refers to the orientations and beliefs of the students about learning that are relevant to cognitive engagement and classroom performance. Further, its components comprise 31 questions that focus on self-efficacy, intrinsic value, and test anxiety.

To obtain the motivational factor the researchers administered the Motivational and Self-Regulated Learning Components of Classroom Academic Performance [17] but only focused on the motivational beliefs section of the said questionnaire.

\section{B. Instrument}

There are two main sources of data. The first source of data is the official final grades of the students. This is the submitted grade of the faculty handling the two sections, in which the first section has regular block students and the other has irregular block students. The second source of data come from a survey questionnaire. The said questionnaire is known as the Motivational and Self-Regulated Learning Components of Classroom Academic Performance [17] that focuses on the relationships among student motivational orientation, self-regulated learning, and classroom academic performance. As regards other variances such as cognitive strategy use and selfregulation was not included in this research. The said motivational beliefs section is further classed into intrinsic goal with Cronbach Alpha $(\alpha)$ of 0.80 , selfefficacy with $(\alpha)$ of 0.94 , and test anxiety with $(\alpha)$ of 0.83 .

\section{Sampling}

The participants were chosen using the purposive sampling. The course was selected using the following criteria: 1) the course code should have at least two sections wherein the first section has students under a regular block and the other course code has students under an irregular section and 2) the two sections must be under the same faculty. The students were delimited to sophomore students who are enrolled to BSIS major subjects on 1st and 2nd Terms of SY 2016-2017.

The samples were taken from students taking ISPROG3, under the same professor with two kinds of sectioning $(\mathrm{N}=62)$. To control possible teacher and course bias, observations were derived based on the same class and teacher. The data was collected from the class record submitted by the teacher particularly their student id, final grade, and section. Motivational and Self-Regulated Learning Components of Classroom Academic Performance [17] survey questionnaire will be administered to measure student's motivation. 


\section{Data Collection}

To collect the desired data from the Registrar's Office a request was sent through the chairperson of the Information Systems Program detailing the purpose of the research, the required data, and the expected delivery of the requested data. On the other hand, to administer the survey questionnaire, a request was sent to the concerned faculty handling the two sections through the chairperson of the abovementioned program. The request contained the sections that will be included in the survey, the date of the supervision of the survey, the time of the survey, and the room number. Ethical policies were observed to protect the respondents of the study.

\section{E. Statistical Analysis}

The research design applied for the study is descriptive and correlational. To describe the characteristics of the data as to distribution and dispersion, measures of central tendency was used. Hypothesis testing is done through correlation and analysis of variance to test significance. The alpha level is set to 0.05 .

Logistic regression was used to test course performance (independent) and sectioning (dependent, dichotomous $(0=$ irregular, $1=$ regular $)$ ) since the dependent variable has a binary category. Omnibus Test of Model Coefficient was used as test of significance. To determine the explanatory power of grades in the model, Cox \& Snelll and Nagelkerke statistics were used to compute the coefficient of determination or $\mathrm{R} 2$.

\section{RESULTS AND DISCUSSION}

\section{A. Discussion of Results}

This section is a presentation and discussion of the results of the study on the relationship of sectioning in academic performance. The main discussion deals with the interactions of the sectioning and the academic performance.

Data were analyzed using IBM SPSS Statistics version 21. Descriptive statistics were used to describe the characteristics of the respondents to include frequencies and percentages. To test the reliability of the instrument Cronbach Alpha was used. To test the extent of relationship of the motivational variables and course performance, Pearson Product Moment was utilized. Logistic Regression and ANOVA statistics were calculated to examine if there were significance of the sectioning with the academic performance (significance level was set at .05).

\section{B. Demographics}

Majority of the respondents were females (83.9 percent), 2nd year (83.9 percent), and regular students (74.2 percent). There was an even distribution of the students in terms of sectioning; regular (58.1 percent) and irregular (49.1 percent). Tables 1 shows the frequency and percentage of the demographic profile.

Table 1. Demographic Profiles of the Students

\begin{tabular}{|c|c|c|c|}
\hline \multicolumn{4}{|c|}{ DEMOGRAPHIC VARIABLES } \\
\hline Variable & & $\mathrm{N}$ & $\%$ \\
\hline \multicolumn{4}{|l|}{ Gender } \\
\hline & Male & 10 & $16.1 \%$ \\
\hline & Female & 52 & $83.9 \%$ \\
\hline \multirow[t]{3}{*}{ Year Level } & 2nd & 52 & $83.9 \%$ \\
\hline & $3 \mathrm{rd}$ & 5 & $8.1 \%$ \\
\hline & 4th & 5 & $8.1 \%$ \\
\hline \multicolumn{4}{|l|}{ Section } \\
\hline & Irregular & 26 & $41.9 \%$ \\
\hline & Regular & 36 & $58.1 \%$ \\
\hline \multicolumn{4}{|l|}{ Type } \\
\hline & Regular & 46 & $74.2 \%$ \\
\hline & Shiftee & 4 & $6.5 \%$ \\
\hline
\end{tabular}

\section{Instrument and Reliability}

Using Cronbach's Alpha the computed reliability was 0.886 based on 31 variables to measure motivation. For the summary of item statistics, the item means is 5.26 and item variances 2.06 . These variables were used to measure as mediating factors for sectioning and academic performance. The reliability scale of the 31 items were found to be highly acceptable.

\section{Grades and Sections}

A one-way between subjects ANOVA was conducted to compare the effect of academic performance in ISPROG3 on various sections. The mean of the grades for irregular class is 78.62 (SD = 10.798) and regular $87.87(\mathrm{SD}=7.368)$. Based on $95 \%$ confidential interval the academic course performance are CI[74.26, 82.48] for irregular, and CI[85.36, 90.37] for regular block. The boxplot illustrates the distribution of the grades between the two sections. 


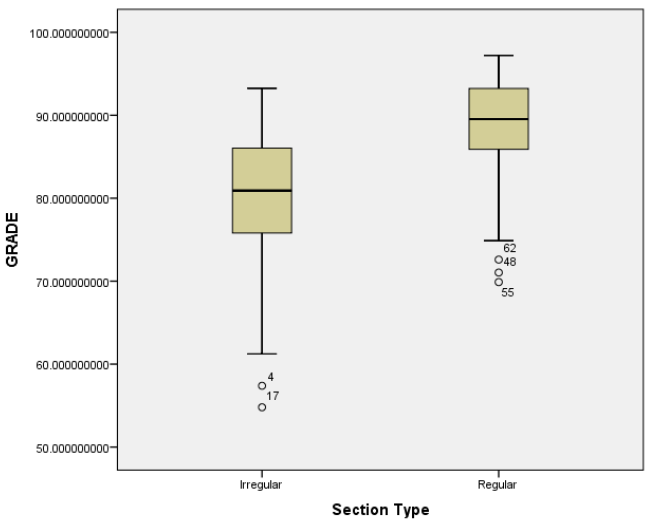

Fig. 2. Boxplots of Grades of Regular and Irregular Sections.

Based on F-test calculation, there was a significant effect of sectioning class on the academic performance at the $\mathrm{p}<.05$ level $[(\mathrm{F}(1,60)=16.095$, $\mathrm{p}=.000]$. This is presented in Table 2 below.

Table 2. One-Way ANOVA Statistics Between Grades and Sections

ANOVA
\begin{tabular}{|l|r|r|r|r|r|}
\hline & \multicolumn{1}{l|}{ GRADE } \\
\hline & Sum of Squares & \multicolumn{1}{c|}{ df } & Mean Square & F & Siq. \\
\hline Between Groups & 1291.714 & 1 & 1291.714 & 16.095 & .000 \\
Within Groups & 4815.463 & 60 & 80.258 & & \\
Total & 6107.177 & 61 & & & \\
\hline
\end{tabular}

A logistic regression model was generated to determine the odds of grades explaining sectioning (dichotomous variable, $0=$ irregular, $1=$ regular). The Model Summary (Table 3) states the -2Loglikelihood for the model and revealed it has a moderate explanatory power as indicated by the R2. The Cox \& Snell R2 implies that course performance contributes to sectioning by $20.7 \%$. Nagelkerke R2 showed a higher explanatory value with $27.8 \%$. The Ominibus Test of Model Coefficient showed that the model is highly significant $(\mathrm{p}=.000, \mathrm{df}=1$, chi=14.366).

Table 3. Logistic Regression Summary

\begin{tabular}{|c|c|c|c|}
\hline Step & $\begin{array}{c}-2 \text { Log } \\
\text { likelihood }\end{array}$ & $\begin{array}{c}\text { Cox \& Snell R } \\
\text { Square }\end{array}$ & $\begin{array}{c}\text { Nagelkerke R } \\
\text { Square }\end{array}$ \\
\hline 1 & $69.964 \mathrm{a}$ & .207 & .278 \\
\hline
\end{tabular}

a. Estimation terminated at iteration number 5 because parameter estimates changed by less than .001 .

Linear Regression Formula of Section and Grade: The model indicates that for every single unit increase in grade, there is an equivalent 1.385 increase in sectioning.

Predicted probability of section $=(0.325)+$ 1.385(Grade)

\section{E. Grades and Motivation}

Using ANOVA, the results shows that there was NO significant effect of grade and the total of the motivational factors $[\mathrm{F}(6,49)=1.404, \mathrm{p}=. .232]$. The motivation factor mean of the irregular class is 161.308 ( $\mathrm{SD}=21.011)$ while the regular class registered a mean of $164.222(\mathrm{SD}=21.449)$. The SPSS result is shown in Table 4.

Table 4. Grades and Motivation Significance Test (ANOVA)

ANOVA
TOTAL
\begin{tabular}{|l|r|r|r|r|c|}
\hline & \multicolumn{1}{c|}{$\begin{array}{c}\text { Sum of } \\
\text { Squares }\end{array}$} & \multicolumn{1}{c|}{ df } & Mean Square & F & Sig. \\
\hline Between Groups & 3694.818 & 6 & 615.803 & 1.404 & .232 \\
Within Groups & 21488.539 & 49 & 438.542 & & \\
Total & 25183.357 & 55 & & & \\
\hline
\end{tabular}

A Pearson product-moment correlation coefficient was computed to assess the relationship between the grade and motivation. There was a slight positive correlation and but no significance between the two variables $[\mathrm{r}=.161, \mathrm{n}=61 \mathrm{p}=.210$.].

\section{F. Motivation and Sections}

There is no significant difference between the section and motivation $[\mathrm{F}(1,60)=.284, \mathrm{p}=.596]$. In other words, the result showed that there is no difference in the motivation of regular and irregular sections.

\section{G. Secondary Findings}

While there was a significant relationship on the result of the ANOVA $(\mathrm{p}<.05)$ and Omnibus Test statistics between grade and section, there was no significant effect of motivation on grade ( $p>.05)$ it is necessary to examine the individual motivational factors that further explains any relationship with grades.

Significant differences were found in Intrinsic $(\mathrm{p}=.014, \quad \mathrm{r}=.312), \quad$ Self-Efficacy for Learning Performance $(\mathrm{p}=.30, \mathrm{r}=.275)$ and Test Anxiety $(\mathrm{p}=.036, \mathrm{r}=-\mathrm{-} .267)$. The study showed that there were positive and significant factors between grade and intrinsic and self-efficacy, while test anxiety factor was negatively correlated and significant.

Table 5. Summary of Grades and Motivational Factors Correlation 


\begin{tabular}{|c|c|c|}
\hline \multicolumn{3}{|c|}{ GRADE AND MOTIVATIONAL FACTORS CORRELATION } \\
\hline Factor & $\mathrm{p}$ & $\mathrm{r}$ \\
\hline Intrinsic & $0.014^{*}$ & 0.312 \\
\hline Self-Efficacy for Learning Performance & $0.03^{*}$ & 0.275 \\
\hline Test Anxiety & $0.036^{*}$ & 0.267 \\
\hline Extrinsic & 0.865 & 0.022 \\
\hline Task Value & 0.06 & 0.24 \\
\hline Control of Beliefs & 0.363 & 0.118 \\
\hline
\end{tabular}

* significant ( $p<.05)$

Figure 3 illustrates the path analysis by their computed probability values. The path shows that sectioning has a direct effect on grade. Motivation as a whole does not relate with sectioning; however, some of its factors mediate with grade.

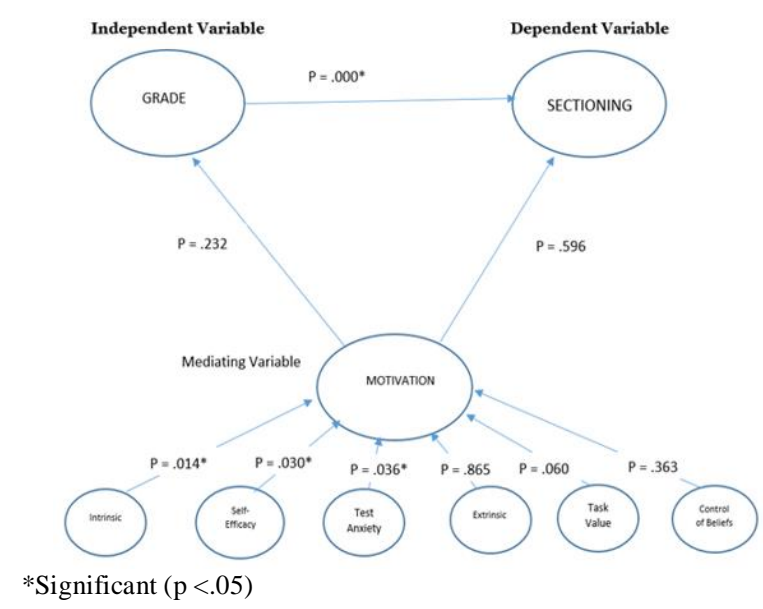

Fig. 3. Overall Summary of Results

\section{Conclusion}

The study arrived with the following conclusions:

1. The study concludes that sectioning significantly relates to academic performance and grade have a modest explanatory power to sectioning.

2. Motivation as a whole does not influence the students' grades.

3. Certain factors of motivation such as intrinsic, self-efficacy for learning and test anxiety suggest a significant relationship with grade not necessarily based on effect of sectioning.

4. Motivation has no bearing on the various sections whether they are regular or irregular.

5. It is also possible that students who have been together in almost all the subjects have developed collaborative network thereby increasing their capacity to learn.

The researchers recommend that school administrators/managers examine the results of this study to make adjustment in the rationale of dividing classes into block and irregular section out of scheduling expediency, financial consideration, manpower resource allocation, and the like.

For teachers, the research maybe helpful to increase awareness on the effects of block and irregular sectioning. In addition, it is necessary to make a further study to build deeper understanding on why sectioning affects learning aside from those mentioned in the research.

\section{REFERENCES}

[1] Biesinger, K. D., Crippen, K. J., \& Muis, K. R. (2008). The impact of block scheduling on student motivation and classroom practice in mathematics National Association of Secondary School Principals. NASSP Bulletin, 92(3), 191-208.

[2] Maltese, A. V., Dexter, K. M., Tai, R. H., \& Sadler, P. M. (2007). Breaking from tradition: Unfulfilled promises of block scheduling in science. Science Educator, 1-7.

[3] Deuel, L. (1999). Block scheduling in large, urban high schools: Effects on academic achievement, student behavior, and staff perceptions. The High School Journal, 14-25.

[4] Rikard, L. G., \& Banville, D. (2005). High school physical education teacher perceptions of block scheduling. The High School Journal, 26-34.

[5] Veal, W. R., \& Flinders, D. J. (2001). How block scheduling reform effects classroom practice. The High School Journal, 21-31.

[6] Grant, D. (2001). Using block courses for teaching logistics. International Journal of Physical, 574-585.

[7] Lare, D., Jablonski, A. M., \& Salvaterra, M. (2002). Block Scheduling: Is it Cost-Effective? National Association of Secondary School Principals. NASSP Bulletin, 54-71.

[8] Jenkins, E., Queen, A., \& Algozzine, B. (2002). To block or not to block: That's not the question. The Journal of Educational Research, 196-202.

[9] Marchant, G. J., \& Paulson, S. B. (2001). Differential school functioning in a block schedule: A comparison of academic profiles. The High School Journal, 1220.

[10] Bair, M., \& Bair, D. (2010). Scheduling inequality in math and science: How trimesters hurt students at risk of academic failure. American Secondary Education, 78-94.

[11] Zepeda, S. J., \& Mayers, S. (2006). An Analysis of Research on Block Scheduling. SAGE Journals, 76(1), 137-170. 
[12] Gruber, C. D., \& Onwuegbuzie, A. J. (2001). Effects of block scheduling on academic achievement among high school students. The High School Journal, 3442.

[13] Dexter, K. M., Tai, R. H., \& Sadler, P. M. (2006). Traditional and block scheduling for college science preparation: A comparison of college science success of students who report different high school scheduling plans. The High School Journal, 22-23.

14] Müller, T., \& Murray, K. (2010). Comprehensive approach to student sectioning. Annals of Operations Research, 249-269.

[15] Rettig, M. D., \& Canady, R. (2001). Block Scheduling: More Benefits than Challenges. Response to Thomas. National Association of Secondary School Principals. NASSP Bulletin, 85(628), 78-86.

[16] Kienholz, K., Segall, N., \& Yellin, D. (2003). The block: Implications for secondary teachers. Kappa Delta Pi Record, 39(2), 62-65.

[17] Pintrich, P. R., \& De Groot, E. V. (1990). Motivational and Self-Regulated Learning Components of Classroom. Journal of Educational Psychology, 82(1), 33-40. 